\title{
Portable technologies at the museum
}

ConNIE Svabo*

\begin{abstract}
A topic of interest in contemporary museum studies is how digital technologies contribute to museum visitor experiences. Building on insights from media and technology studies that new media should be understood for how they overlap with old media, the article reports an ethnographic study of the intersections between the exhibition at a modern museum of natural history and three portable technologies - one of which is digital. Mobile phone cameras, exercise pamphlets and dress-up costumes link visitors with an exhibition, but they simultaneously shape this relation in their own specific directions. This is shown by drawing on the concept of mediation as it is developed by philosopher Michel Serres and philosopher of technology Bruno Latour. The article is based on the Ph.D. thesis entitled "Portable Objects at the Museum", defended at Roskilde University on 22 September 2010.

Key words: Visitor experience, museum communication, information and communication technology, media convergence, spaces of experience, mediation, natural history.
\end{abstract}

INTRODUCTION: OVERLOOKED MATERIALITY IN VISITOR EXPERIENCES

Throughout the past three decades, international museum research has increasingly emphasised museum visitor experiences. Museums have a responsibility, not only in relation to collection and documentation, but also for communication with the public (Bayne, Ross and Williamson 2009; Macdonald 2005). Hooper-Greenhill argues that a museum exhibition is a medium for mass communication and therefore should be explored for its abilities to communicate with the public $(1995 ; 2006)$. Hein points out that there is a huge difference between didactic intent and the learning which emerges in a situation, and he links this insight to museum exhibitions in particular. Situations which are beneficial in terms of learning are often open and ambiguous - it is possible for the learner to exert influence on them and, due to this openness, it is quite difficult to predict how a situation develops and what meaning a person will make out of it. According to Hein, a rich and complex environment such as a museum exhibition is a good site for learning, but it also holds numerous possible forms of interaction, and for this reason it is quite possible that the learner will focus on something different from 
136 what the educator had in mind (Hein 1995: 189; 1998). These are but two museum scholars who point out that there is a need for in-depth knowledge about the museum visit. A primary work on this topic is Falk and Dierking's The Museum Visitor Experience (1992), which points to the fundamentally social character of the museum experience. Visitors regard a museum visit as a social outing, like going to a park or some other leisure site. The museum visit is both affected by social situation and by the personal history, taste and preferences of the collective of museum visitors. These issues are highlighted by Falk and Dierking and have been used as point of departure in later research, in a Danish context by Grøn (2007), for example. Less attention has been devoted to the more material influences on museum visits; particularly how mediating materials and technologies contribute to constituting museum visitors' subjectivity and modes of experiencing. A notable exception to this tendency to focus on the social - rather than the sociomaterial - is Hetherington's study of how Braille signs, easy access ramps, stairs, audio guides and a tactile book mediate a museum exhibition and in this process constitute the embodiment of a visually impaired person (Hetherington 2003:107).

\section{HYBRID MUSEUM VISITORS}

Information and communication technologies are rapidly moving away from desk tops, and instead permeating everyday spaces and situations. The omnipresence of digital technologies makes it difficult to ignore the hybrid character of the human subject. For the same reason, digital technologies are increasingly receiving attention in the field of museum studies as well. As such, this orientation is helping to fill a void - the previously-mentioned lack of attention towards the hybrid, sociomaterial constitution of museum visitors. Museum researchers attentive to this new digital dimension of museum visits advocate the promising potential of "new"technologies in museum communication (Kahr-Højland 2007; Hansen et al 2009; Schroyen et al 2007; Tallon 2008; Gammon and Burch 2008; Mensch 2005), but there seems to be a lack of empirically based research on how digital technologies contribute to museum experiences - perhaps because of the novelty of the topic. After a review of existing research, Falk and Dierking report that there is no clear picture of the relationship between museum-based meaning making and digital technologies (Falk and Dierking 2008). There is thus a need for research which looks into this topic - and it is worth noting that it is not sufficient to explore digital technologies as isolated phenomena. Researchers working with media, information and communication technologies point out that new technology should be understood as forming part of media convergences in which old and new media overlap (Ito 2008; Falkheimer and Jansson 2006). This implies that a museum exhibition may be understood as a site which is saturated by various kinds of information and communication technologies. Various forms of communication converge in a museum context, as the museum theme may be communicated by exhibits, signs, posters, pamphlets, brochures, guided tours, computerbased information kiosks, handheld digital information providers and human guides. Communication practices and technologies coexist, overlap and intersect.

Summing up, there is a need for in-depth 

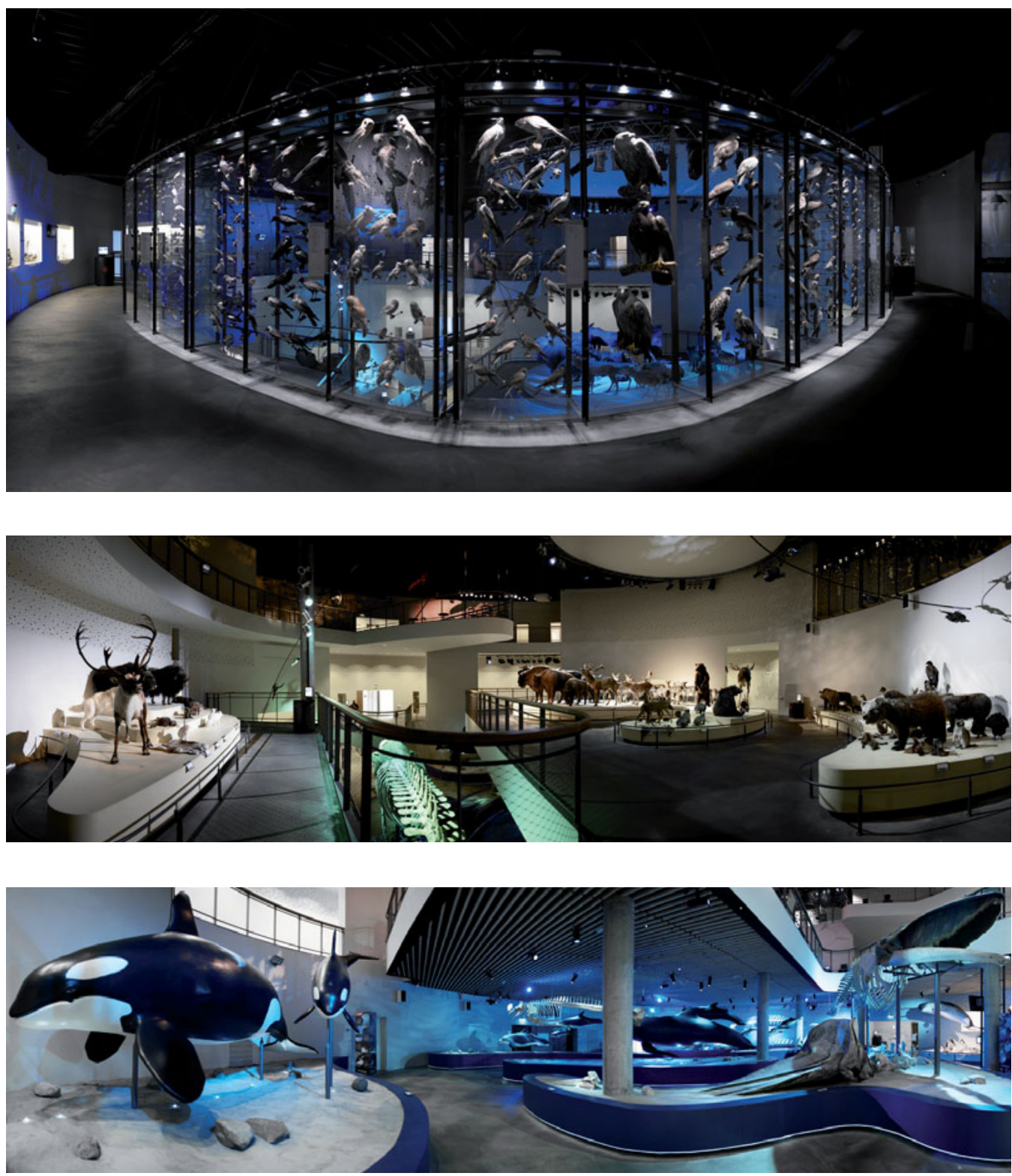

Naturama's exhibition is a circular room with three levels: Air, Land and Water. Multimedia is extensively used to create an effect of dramatized nature. Changes in light and sound give the impression of the cycle of day and night. Photographer: 1,2,3: Niels Nyholm / Photopop.dk. 
138 qualitative studies which build comprehensive descriptions of museum visitor experiences in general. Furthermore, there is a particular need for studies which pay attention to how various communication technologies contribute to museum visits.

The growing interest in mobile, digital technologies potentially tags along with sensitivity towards the hybridity of museum visitors. The orientation towards mobile technologies may be broadened to encompass not only digital media, but also all sorts of other devices that exert influence on museum visits in various ways. This was a central point in the Ph.D. study I carried out at the Naturama museum of natural history in Denmark. I found various forms of "hybrid visitors", some of which were hybrids between mobile phone cameras and visitors. Others were hybrids between exercise pamphlets and visitors or animal costumes and visitors.

\section{CASE STUdY: NATURAMA}

Naturama is a modern museum of natural history, which opened in 2005 as a rebuilt version of the earlier Svendborg Zoologiske Museum, founded in 1935 and located on the island of Fyn, in Denmark. The museum is an independent institution, which is stateapproved with the status of museum. It receives a limited government grant, is state-subsidized to carry out specific tasks, and is subject to Danish museum legislation. This obliges the museum to carry out activities of collection, registration, research and communication, all with the purpose of maintaining the natural historical legacy and making this accessible to the public. A central task of the museum is to continuously develop its role as a knowledge and experience centre and to contribute to cultural and educational development in society.

The museum is what in a Danish context can be denoted a medium-sized museum: with 65,509 visits in 2009 and somewhere between 20 and 30 employees, depending on the time of year. Children and young people under 18 account for half of the museum visits. The museum has a 4-star rating from Danish Tourist Attractions, and was nominated for the Danish Museum Award in 2006 and for the European Museum Award in 2007.

The name Naturama is a combination of nature and drama, and was chosen to symbolize the experience the museum hopes to give its visitors - an experience of dramatized nature. The permanent exhibition in the museum is divided into three levels in descending order: Air, Land and Water: Air on the top floor, Land in the middle, and Water on the ground floor. The floor divisions relate to three categories of animals - those that live in the air, on land, and in water. In the exhibition, traditional dioramas are replaced by a minimalist exposition of taxidermic mounts garnished with an elaborate multimedia show. An audiovisual show plays continuous 90minute loops that use light and sound to give an impression of the twenty-four hours of day and night coming and going. Light and sound change from the energetic rhythm of sunrise to calm, starry night and the accompanying sounds range from the quiet scuffle of a badger to a trickle of rain and roars of thunder. Signs and posters are reduced to a minimum in the streamlined design, and instead computerbased information kiosks are dotted throughout the exhibition.

The museum is an interesting case, because it is a modern museum that is saturated by a range of different mediation technologies. The 
museum uses digital technologies in the form of multimedia shows, video, interactive exhibits, information kiosks, PDA-based audio guides and the museum website. Furthermore, the museum is an example of a museum reality in which digital technologies are put to work alongside other communication practices such as guided tours, printed materials, special events, workshops, concerts and enactment activities. It is an example of a media reality in which new and old media coexist.

\section{METHOD: ETHNOGRAPHY OF PORTABLE TECHNOLOGIES}

Based on the need for in-depth qualitative studies of museum visitor experiences, I carried out an ethnographic case study of museum visits. I used qualitative methods to produce data about the encounters between visitors and the museum exhibition. Field work was carried out over a period of 14 months from April 2007 until June 2008, and several follow-up visits have been conducted, the last one in the spring of 2011. During the fieldwork, I used the techniques of participant observation, qualitative interviews, and audio and video recording. I carried out 39 days of observation at the museum, 21 of these days focused on visitor interactions, and I carried out several interviews, 19 of which were with visitors. Interviews and observations were with visitors of all ages, but gradually focused on visitors who are the primary users of exercise pamphlets, mobile phone cameras and animal costumes - children up till the age of 13 and the visitors accompanying them. The methods and techniques employed are extensively described in my Ph.D. thesis (Svabo 2010: 133).

During my ethnographic fieldwork at the museum, I became aware that three portable technologies - mobile phone cameras, exercise pamphlets and animal costumes - are central when visitors engage with the museum; all of these three technologies are frequently used by visitors.

\section{THREE POPULAR TECHNOLOGIES}

Mobile phone cameras are now an integral part of the day-to-day lives of children and young people. A 2009 survey carried out by the Danish Media Council for Children and Young People showed that 81 per cent of the 9-10 year olds, 94 per cent of 9-16 year olds, and for the age group 14-16, 99 per cent have mobile telephones. Children take their mobile phones with them wherever they go, even when they visit a museum. At Naturama, children and young people use their mobile phones as cameras to take pictures of animals on display.

Exercise pamphlets are also very commonly used at the museum. 8,737 pamphlets were in circulation in 2009, with an annual total of 65,509 visitors - around half of these under age 18. This means that almost one third of the children who visit Naturama have an exercise pamphlet with them, and because it is common that more than one visitor is engaged with the same pamphlet - for example when families collaborate - the actual proportion of visitors, both children and adults, who are influenced by a pamphlet is quite large.

By comparison, it is striking that visitor practices at Naturama reveal that visitors systematically ignore portable digital assistants (PDAs) provided by the museum to be used as audio guides. Only 73 PDAs were borrowed in 2009. In a competition for visitors' attention, exercise pamphlets and mobile phones thus out-run the PDA by a long way; the PDA hasn't even gotten out of the starting block 

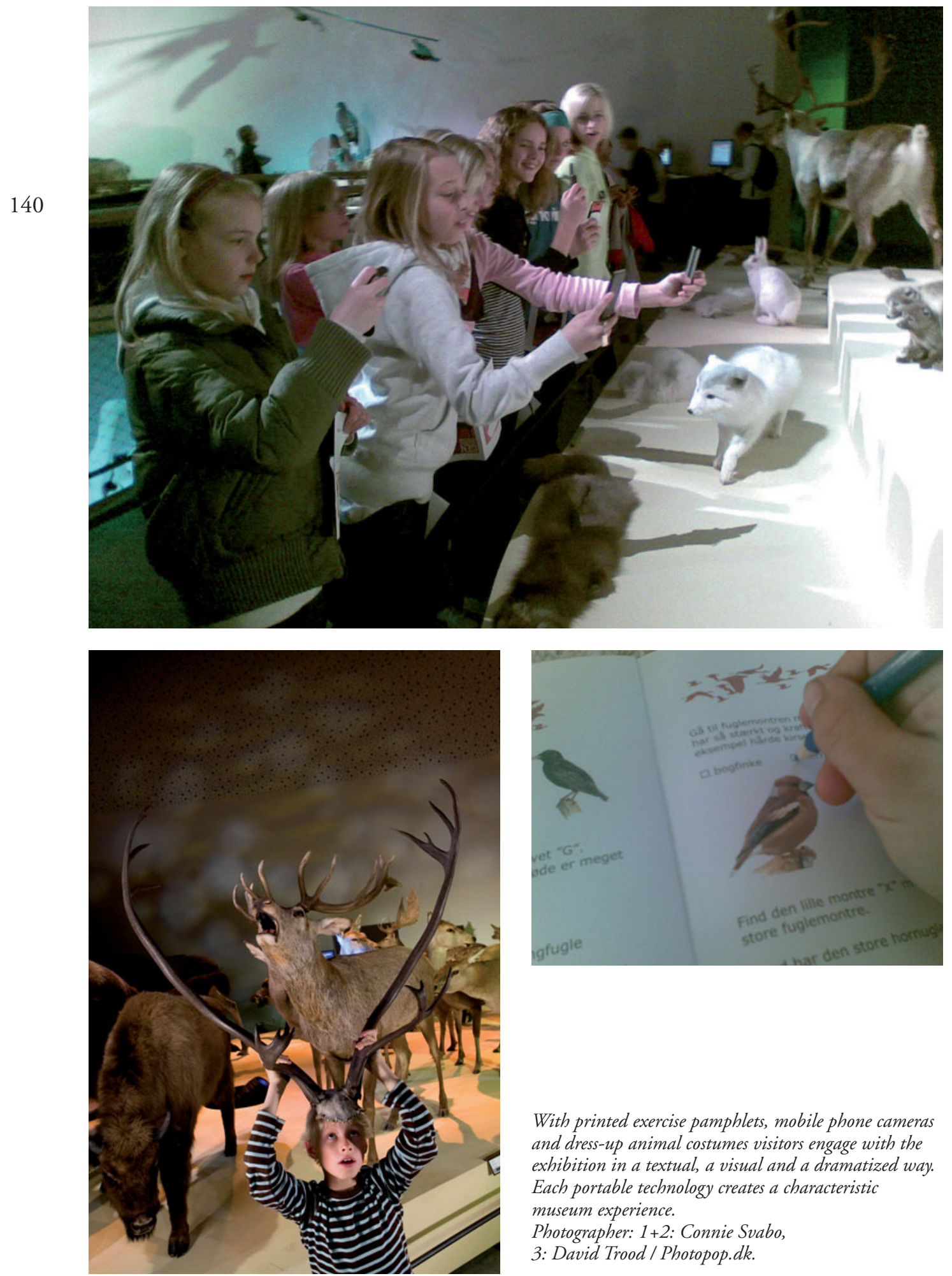

With printed exercise pamphlets, mobile phone cameras and dress-up animal costumes visitors engage with the exhibition in a textual, a visual and a dramatized way. Each portable technology creates a characteristic museum experience.

Photographer: 1+2: Connie Svabo,

3: David Trood/ Photopop.dk. 
when pamphlets and phones are racing through the exhibition. And these technologies on the move are occasionally accompanied by another running technology: the animal costume.

At Naturama, it is common to see children dressed in one of the 15-20 animal costumes that the museum places at the disposal of visitors, and when children wear such costumes they play around, attack and chase each other through the exhibition. Although a costume is not what we normally would consider a technology, it can be perceived as such if it is considered in terms of its communicative intent and use. The museum uses these costumes as a way of staging a particular kind of museum experience, and in this sense it is a communication technology. This broad understanding of technology may be given further perspective by the fact that a central point in Latour's technology studies is to draw attention to mundane and overlooked technologies (Latour 2005, Michael 2000).

\section{Key CONCEPT: MEdiATION AS CONNECTION AND DISTORTION}

Exploring how the three portable technologies participate in museum visits - how they establish connections between museum visitors and the museum exhibition and what kind of influence they have on museum experiences contributes to building an understanding of the museum as a site of media saturation. The three portable technologies provide a useful starting point for unravelling media convergences in the museum exhibition, where various information and communication technologies are in play at the same time - old and new, digital and not. The exhibition holds classic exhibits garnished with computers and interactive exhibits, and furthermore the three phones, exercise pamphlets and animal costumes. These overlapping communication technologies and the roles they play when visitors relate to the museum exhibition can be fruitfully explored by the term mediation. To mediate is to associate, to communicate between two parties, and - inspired by the work of philosopher and cultural theorist Michel Serres and philosopher of technology Bruno Latour - the term mediation can be expanded further. Mediation understood in a Serres and Latour sense highlights the simultaneous establishing of a connection and the distortion which takes place in the connection. Mediation establishes a relation as well as creating a kind of twisted version of that which is mediated, one might say that the mediator both connects and objects. Mediation is not a simple transportation of meaning, unaltered, through a mute and passive intermediary. It is invention, distortion and even to a certain degree betrayal. Mediation the making of relations - has transformative aspects; the mediator changes what it mediates. With the connection also emerge displacement, drift and invention (Latour 2005). Looking at technologies as mediators implies considering what it is that they do; how do they make relations, form them, shape them and hold them in place and what happens to the linked parties in this process; how are the linked entities formed in and by the mediation? In relation to the museum visit: how is the visitor shaped as he or she is associated to the exhibition, and what kinds of trans-formation do the various mediating technologies bring? And the same question can be asked about the exhibition; what form does the exhibition assume; how is it transformed in the mediation? 
142 Findings: PoRTABLE TECHNOLOGIES EACH MEDIATE A MODE OF VISITING

When visitors' frequent engagements with portable technologies are coupled with the notion of mediation, we can see that the three portable technologies act as mediators which both relate and transform the visitor and the exhibition, and thus drastically shape the visit. The subject matter of natural history is enacted in ways which closely connect to the portable technology in use. Each portable object mediates a characteristic mode of visiting; a characteristic pattern of activity and interaction.

Visitors with exercise pamphlets conjure up an exhibition which assumes the form of text; information is stashed in computers and on signs and visitors dig information out of these compartments and move it to the blank lines which exercise pamphlets ask them to fill out. With exercise pamphlets emerges a scholarly and factually oriented enactment in which the exhibition is transformed into a site for finding answers and the child is a note-taker who moves information around.

Visitors with mobile phone cameras conjure up an exhibition which assumes the form of visual images. Children take pictures of animals which they find impressive or beautiful. With mobile phone cameras emerges a relentless

\begin{tabular}{|c|c|c|c|}
\hline & Exercise pamphlet & Mobile phone camera & Animal costume \\
\hline Exhibition enacted as & Deposit of information & Fashion show & Nature reserve \\
\hline Action & $\begin{array}{l}\text { Visitor moves informa- } \\
\text { tion, traverses exhibi- } \\
\text { tion. Walks at a high } \\
\text { pace, follows trail. } \\
\text { Purposeful search with } \\
\text { pen and paper in hand. } \\
\text { Stops once in a while } \\
\text { and writes. Or: is statio- } \\
\text { nary at computer, } \\
\text { extracting information. }\end{array}$ & $\begin{array}{l}\text { Visitor makes images. } \\
\text { Moves around at a slow } \\
\text { pace, occupied som- } \\
\text { nambulistic (present/ } \\
\text { absent). } \\
\text { Stops once in a while, } \\
\text { holds arm up, takes } \\
\text { picture, looks at image, } \\
\text { moves on. }\end{array}$ & $\begin{array}{l}\text { Visitor plays. Crawls, } \\
\text { attacks other visitors, } \\
\text { scratches, utters guttural } \\
\text { sounds. Wild, predatory } \\
\text { movement. }\end{array}$ \\
\hline Visitor enacted as & $\begin{array}{l}\text { Archaeologist, note- } \\
\text { taker }\end{array}$ & Photographer & Animal \\
\hline Interaction produces & Text, inscription & Images & Play, performance \\
\hline Relates to & $\begin{array}{l}\text { Lists of inventory, } \\
\text { multiple choice tests, } \\
\text { school, work }\end{array}$ & $\begin{array}{l}\text { Photo album, leisure, } \\
\text { tourism, vacation }\end{array}$ & $\begin{array}{l}\text { Costumes, masks, } \\
\text { carnival, drama }\end{array}$ \\
\hline $\begin{array}{l}\text { Form of } \\
\text { understanding }\end{array}$ & $\begin{array}{l}\text { Facts-based, } \\
\text { instrumental }\end{array}$ & Aesthetic, visual & Bodily, imagined \\
\hline
\end{tabular}


accumulation of pictures in which digital images are collected and deposited in jeans pockets. The exhibition presents itself as visual images and the visitor is a photographer chasing beauty.

Visitors with animal costumes conjure up an exhibition which is the site for embodied, imagined and dramatized encounters - visitors snarl, growl and hunt while in the exhibition. The exhibition turns into a nature reserve, hunting ground and habitat roamed by animal children on the move.

Relations between museum visitors and the exhibition are established with the three portable technologies, but the relation between the visitor and the exhibition is simultaneously manipulated in a characteristic direction by each portable technology. Each mediator creates its own version of the exhibition. The exhibition is enacted in three related - but not congruent - versions.

\section{DISTORTION IS NOT PROBLEMATIC}

When portable technologies are at play they create distorted versions of the exhibition. Portable technologies stitch together a version of the exhibition which fits them. They fixate and hold the exhibition, and they transform and distort it. From an agenda of knowledge transmission it may be considered problematic that children who are engaged with mobile phone cameras do not engage with animals in terms of biological facts such as information about names, species, habitat and food. Reciprocally, from an aesthetic agenda it may considered problematic that children who are engaged in exercise pamphlets do not sense the exhibition in terms of beauty, light or sound. Viewing the occurring interactions as problematic from one perspective or other ties in with having specific ideas for what kind of interaction is desired. If the exhibition is seen as a parade of a specific kind of knowledge and if the didactic agenda of the museum is a closed one which does not subscribe to the openness of learning, as pointed to by Hein, the mediation carried out by portable technologies may be considered problematic. The portable technologies may be seen as betrayers. They do not faithfully convey the Word of Science. But the mediation carried out by portable technologies takes on a somewhat less problematic air when the exhibition is pulled down from an imaginary throne. The exhibition is neither God nor Queen. The exhibition itself is a mediator and in this sense, also a broker and a betrayer. It is devised to communicate science, to mediate between natural history and the public. Both the exhibition and the portable technologies are messengers, designated to communicate. Metaphorically speaking we might say that the exhibition archangel is flanked by multiple other angels; seraphs and cherubs. They bear messages, mediate between worlds, and their overlapping interactions are what Serres calls "the intercommunication of message-bearing systems" (1993/1995). The exhibition archangel flanked by other messengers successfully communicates the theme of nature to visitors.

\section{DISCUSSION: DESIGN FOR CONVERGENCE}

The study seeks to contribute to the growing subarea of digital technology in museum communication and experience. The study flattens out the divide between digital and nondigital technologies and confirms the point made in technology studies; that new and old technologies must be understood in terms of overlap and convergence. This is an important 
point to remember in the development of new communication devices; relations between the exhibition and mobile digital technologies must be explicitly contemplated. Mobile digital devices should be designed in a way where they explicitly draw attention to aspects of the exhibition which the museum wants to communicate. This may seem to be a banal point, but reported experiments with developing applications for digital handheld devices for use in museums do not always explicitly reflect on the relation between the digital medium and the exhibition (for an example of this, see Schroyen et al 2007).

Designing the relations between the exhibition and other mediating technologies is a central challenge which emerges at the intersections between various communication technologies. The interaction designer for example may contemplate a computer interface or the interface between a handheld digital device and a user, but this is not sufficient. It is necessary also to contemplate the relation to the spatial design and other communication practices. And here it is worth noting also that designers of museum communication may have to deal with several versions of the same user: the same visitor may very well be engaged in various kinds of mediation, and thus form various hybrids. Within moments, children shift from growling brown bears to task-solving busy-bodies moving information around, and then are clicked into photography. Museum visitors shift and morph as they engage in mediated encounters with the exhibition. This implies that museum communication designers have to not only be able to make singular designs which work well, but also have to be able to imagine user situations which consist of multiple, overlapping and sometimes even competing mediations. It is necessary for both research and practice to be able to tackle the multiplicity of mediations carried out by exhibits, signs, posters, pamphlets, brochures, tours and digital technologies. A museum visit consists of multiple coexisting mediations and the negotiations between them. For this reason it is central to not have a myopic focus on one communication technology, but to explore and build an understanding of the intersections between various communication technologies.

\section{CONCLUSION: MUSEUM EXPERIENCES MEDIATED BY DIGITAL AND MUNDANE TECHNOLOGIES}

In the past thirty years, the field of museum studies has increasingly voiced an interest in how the museum communicates with the public and how the public experiences museums. A contemporary topic of interest in this relation is the role and potential of digital technologies for creating interesting and educational museum experiences. Standing on an insight from technology studies that new and old media should not be counterpoised, but that new media rather should be understood for how they overlap and intersect with old media, the article reports a study of the intersections between various media. The relationships between visitors, a museum exhibition and three portable technologies are explored as they emerge in an ethnographic fieldwork of a Danish museum of natural history. The three technologies are mobile phone cameras, exercise pamphlets and animal costumes. They are studied because they are commonly used by museum visitors and they all contribute to establishing a characteristic relation between the visitor and the exhibition.

Inspired by the work of philosopher and cultural theorist Michel Serres and philosopher 
of technology Bruno Latour, the intersections between the museum exhibition and three portable technologies are explored as relationships of mediation, which both is the establishment of a relation and the simultaneous distortion of this relation. The three portable technologies establish connections between visitors and the exhibition, and as such are useful museum communication technologies, but each of the three technologies also gives the encounter between the visitor and the exhibition a twist of its own. The multiple, overlapping and intersecting mediations pose both interesting possibilities for and challenges to museum communication design.

\section{LITERATURE}

Bayne, S., Ross, J., Williamson, Z., 2009: “Objects, subjects, bits and bytes: learning from the digital collections of the National Museums", in Museum and Society, Jul 2009 7(2), pp. 110-124.

Falk, J.H., Dierking, L.D., 1992: The Museum Experience, Washington D.C.: Whalesback Books.

Falk, J.H., Dierking, L.D., 2008: "Enhancing Visitor Interaction and Learning with Mobile Technologies", in Tallon, L., Walker, K., 2008: Digital technologies and the museum experience: handheld guides and other media, pp. 19-34, Plymouth, UK: AltaMira Press.

Falkheimer, J., Jansson, A., 2006: (Eds.). Geographies of Communication: The Spatial Turn in Media Studies. Nordicom: Goteborg.

Gammon, B., Burch, A., 2008: "Designing Mobile Digital Experiences”, in Tallon, L., Walker, K., 2008: Digital technologies and the museum experience: handheld guides and other media, pp. 35-62, Plymouth, UK: AltaMira Press.

Grøn, K., 2007: “Undersøgere, hyggere, scannere og kultiverede. En undersøgelse af gæsters oplevelser og oplevelsesstrategier på Trapholt", in Nordisk
Hansen, D.W., Alapetite, A., Holdgaard, N., Simonsen, C., Vilsholm, R.L., 2009: "Location based solutions in the experience centre", in Nordisk Museologi 2009, 1, pp. 44-52.

Hein, G. E., 1995: "Evaluating teaching and learning in museums", in Hooper-Greenhill (ed.): Museum, Media, Message, pp. 189-203, NY: Routledge.

Hein, G. E. 1998: Learning in the Museum, NY: Routledge.

Hetherington, K., 2003: "Accountability and disposal: visual impairment and the museum", in Museum and Society, 1(2) pp. 104-115.

Hooper-Greenhill, E., 1995: "Museums and communication: an introductory essay", in HooperGreenhill, E. (ed.): Museum, Media, Message, pp. 1-14, NY: Routledge.

Hooper-Greenhill, E., 2006: "Studying Visitors", in Macdonald, S., 2006: A companion to Museum Studies, pp. 362-376, Malden, MA: Blackwell

Kahr-Højland, A., 2007: "Brave new world: Mobile phones, museums and learning - how and why to use Augmented Reality within museums", in Nordisk Museologi 2007, 1, pp. 3-18.

Latour, B., 2005: Reassembling the social: an introduction to Actor-Network-Theory, New York: Oxford University Press.

Ito, M., 2008: "Mobilizing the Imagination in Everyday Play: The Case of Japanese Media Mixes", in Drotner, K., Livingstone, S., (eds.): The International Handbook of Children Media and Culture, pp. 397-412, Los Angeles : SAGE.

Macdonald, S., 2005: "Accessing audiences: visiting visitor books", in Museum and Society, November 2005, 3 (3), pp. 119-136.

Mensch, P.v., 2005: "Annotating the environment. Heritage and new technologies", in Nordisk Museologi 2005, 2, pp. 17-27.

Michael, M., 2000: Reconnecting culture, technology 
and nature: from society to heterogeneity, London and New York: Routledge.

Schroyen J., Gabriëls, K., Teunkens, D., Robert, K., Luyten K., Coninx, K., and Manshoven, E., 2007: "Beyond mere information provisioning: a handheld museum guide based onsocial activities and playful learning", in Nordisk Museologi 2007, 1, pp. 30-45.

Serres, M., 1993/1995: Angels: a modern myth, translated by Cowper, F., 1995, Paris: Flammarion.

Svabo, C., 2010: Portable Objects at the Museum, Ph.d. thesis, Institut for miljø, samfund og rumlig forandring, ENSPAC, RUC.

Tallon, L., 2008: "Introduction: Mobile, Digital and Personal", pp. xii-xxv, in Tallon, L., Walker, K., (eds.): Digital technologies and the museum experience: handheld guides and other media, Plymouth, UK: AltaMira Press.

*Connie Svabo, Ph.D., Assistant Professor, Roskilde University

Address: Research Group on Space, Place, Mobility, and Urban Studies (MOSPUS) Dept. for Environment, Society and Spatial Change (ENSPAC)

Roskilde University

Universitetsvej 1, P.O. Box 260

DK-4000 Roskilde

Denmark

Email:csvabo@ruc.dk 